\title{
Plasma Membrane
}

National Cancer Institute

\section{Source}

National Cancer Institute. Plasma Membrane. NCI Thesaurus. Code C13735.

The semipermeable membrane that encloses the cytoplasm of a cell. 